\title{
Procedure rates and outcomes of coronary revascularization procedures in California and New York
}

Joseph S. Carey, MD, ${ }^{a}$ Beate Danielsen, PhD, ${ }^{b}$ Jeffrey P. Gold, MD, ${ }^{\mathrm{c}}$ and Stephen J. Rossiter, MD, ${ }^{\text {a }}$ for the California Cardiac Surgery Initiative

See related editorial on page 1223.
Objective: Background data were obtained on all California hospitals performing coronary artery bypass grafting and percutaneous coronary intervention procedures and compared with reports published by the state of New York to develop a collaborative quality improvement program for cardiac surgery programs.

Methods: The Patient Discharge Database of the Office of Statewide Health Planning and Development was queried for the years 1999-2001. In-hospital mortality and risk factors for coronary artery bypass grafting and percutaneous coronary intervention were obtained by using demographic data and International Classification of Diseases-Ninth Revision-Clinical Modification procedure and diagnosis codes. Risk models were developed by means of logistic regression analysis.

Results: Overall coronary artery bypass grafting mortality was 33\% higher and percutaneous coronary intervention mortality was twice as high in California compared with that in New York. Procedural volume (per unit population) was higher in New York. In high-volume California hospitals ( $>300$ procedures per year), coronary artery bypass grafting mortality was similar (California, 2.42\%; New York, $2.25 \%)$. Excess coronary artery bypass grafting mortality $(>4.0 \%)$ occurred only in low-volume programs. Risk adjustment did not change the volume effect for coronary artery bypass grafting. No volume effect was noted for risk-adjusted percutaneous coronary intervention mortality. There were no obvious differences in risk factors between California and New York. Programs performing relatively fewer coronary artery bypass grafting procedures compared with percutaneous coronary interventions were found to have significantly higher coronary artery bypass grafting mortality after adjusting for volume effects. Percutaneous coronary intervention volume is increasing and coronary artery bypass grafting volume is decreasing in both California and New York.

From the California Society of Thoracic Surgeons, ${ }^{\text {a }}$ Torrance, Calif; Health Information Solutions, ${ }^{\mathrm{b}}$ Rocklin, Calif; and Albert Einstein College of Medicine, ${ }^{\mathrm{c}}$ Bronx, NY.

Supported by a grant from the California Healthcare Foundation.

Read at the Thirtieth Annual Meeting of The Western Thoracic Surgical Association, Maui, Hawaii, June 23-26, 2004.

Received for publication June 23, 2004; revisions received Dec 1, 2004; accepted for publication Dec 17, 2004.

Address for reprints: Joseph S. Carey, MD, 3475 Torrance Blvd, Suite B-1, Torrance, CA 90503 (E-mail: careyjs@earthlink.net).

J Thorac Cardiovasc Surg 2005;129:1276-82

0022-5223/\$30.00

Copyright (C) 2005 by The American Association for Thoracic Surgery

doi:10.1016/j.jtcvs.2004.12.043
Conclusions: Excess coronary artery bypass grafting mortality in California is related to the large number of low-volume programs. Excess percutaneous coronary intervention mortality might be related to case selection or timing of intervention. A relationship between percutaneous coronary intervention volume and coronary artery bypass grafting mortality is suggested in which increasing percutaneous coronary intervention volume relative to coronary artery bypass grafting volume might have the effect of shifting patients with undefined higher risk characteristics to coronary artery bypass grafting.

I n-hospital mortality is often used as a surrogate for quality in performance evaluation of medical and surgical services. In response to increasing expenditures for surgical procedures, such as coronary artery bypass grafting (CABG), and concerns about the availability and accuracy of provider-specific comparative data, mandatory reporting programs have been implemented in several states. New York has had a program managed by the New York State Department of Health in 
conjunction with the Cardiac Advisory Committee for 15 years, which currently includes public release of hospitaland physician-specific mortality for all cardiac surgery and coronary interventional procedures. California has had a program that requires reporting of outcomes of all hospital admissions to the Office of Statewide Health Planning and Development (OSHPD). However, there has been no requirement of reporting in-hospital mortality to the public until a recent upgrade of the law was passed (California Senate Bill 680).

The California Society of Thoracic Surgeons (CASTS), as well as the California Chapter of the American College of Cardiology and the California Medical Association, supported the mandatory reporting law. The medical groups were able to participate in the appointment of 6 physicians to the 9-member Cardiac Advisory Board. A critical review process was required to allow individual approval by each physician whose data were to be reported to the public. The law, however, requires only reporting of CABG in-hospital mortality. Recognizing that reporting of mortality does not constitute a quality improvement program, officials at OSHPD asked the CASTS to develop one.

The California Cardiac Surgery Initiative (CCSI) was established by the CASTS and the California Healthcare Foundation as a voluntary collaborative quality improvement program to facilitate compliance with SB-680, to review outcomes, and to share best practices. An initial goal was to examine background data on all hospitals performing cardiac surgery and interventional coronary procedures in California.

The outcome data accumulated by OSHPD, know as the patient discharge database (PDD), can be queried for research purposes. We recently queried the PDD to study the relationship between hospital volume and outcome across California hospitals performing cardiac surgery. ${ }^{1}$ We noted that the in-hospital mortality of CABG and percutaneous coronary intervention (PCI) procedures was higher in California compared with that reported by New York. The present report further examines this observation and attempts to explain its potential causes.

\section{Methods}

The OSHPD PDD is an administrative database aggregated from a 2-page "patient discharge abstract" produced from the clinical record of every patient discharged from an acute- or subacute-care facility. Demographic data and International Classification of Diseases-Ninth Revision-Clinical Modification (ICD-9-CM) diagnosis and procedure codes are abstracted by medical record personnel. The OSHPD PDD was queried for the years 1997 through 2001 by using ICD-9-CM codes to identify cardiac surgical and interventional procedures performed in California. For the present report, CABG only was selected as 36.10 through 36.19 , excluding other cardiac surgical codes $(35.10-35.39,35.50-35.95,37.31-37.5,38.35,38.45$, and 33.6); PCI only was selected as $36.01,36.02,36.05,36.06$, and
36.09, excluding 36.10 through 36.19 and other cardiac surgical codes. A patient having PCI and CABG during the same hospitalization was included in the CABG group, as is the custom in New York.

Risk factors used for risk models were determined by using diagnosis codes. We used logistic regression analysis to determine the effect of risk factors on the mortality outcomes. The following demographic risk factors were analyzed: age categorized as 18 to 39,40 to 44,45 to 49,50 to 54,55 to 59,60 to 64,65 to 69,70 to 74,75 to 79,80 to 84,85 to 89 , and 90 years or older (treating age as a continuous variable in the regression model led to the same conclusions); race categorized as white, black, Asian-Pacific Islander, and "other"; ethnicity categorized as non-Hispanic and Hispanic; and sex categorized as male and female. The models also included the following clinical risk factors (if applicable, ICD9-CM codes are shown in parentheses): dialysis (39.95, 54.98); diabetes (250.xx); cerebrovascular disease (430.xx-438.xx); chronic obstructive pulmonary disease (490.xx, 494.xx, 496.xx); peripheral vascular disease $(440 . x x, 441.2 x, 441.4 x, 441.7 x$, $441.9 \mathrm{x}, 443.1 \mathrm{x}, 443.8 \mathrm{x}, 443.9 \mathrm{x}, 447.1 \mathrm{x}, 557.1 \mathrm{x}, 557.9 \mathrm{x}, \mathrm{v} 43.4 \mathrm{x})$; renal failure $(403.11,403.91,404.12,404.92,585 . x x, 586 . x x$, v42.0x, v45.1x, v56.0x, v56.8x); cardiomyopathy (425.xx); cardiogenic shock (785.51); acute myocardial infarction (410.xx, admitted through the emergency department); congestive heart failure (428.0x, 428.1x, 428.9x, 398.91, 402.21, 402.11, 404.03, 404.11, 404.13, 404.91, 404.93); prior CABG surgery (V45.81); emergency status (unscheduled admission through emergency department with procedure performed on admission date); prior PCI (for CABG model); PCI performed on same date as CABG; heart catheterization (for CABG model); and heart catheterization performed on same date as CABG.

New York data were obtained from information published on the New York State Department of Health Web site. We used the most recent reports for CABG (1999-2001) and PCI (1999-2001). The New York data are abstracted from the clinical record, including the risk factors. The continuity-adjusted $\chi^{2}$ test was used to determine differences in rates between California and New York.

\section{Results}

\section{Incidence and Mortality}

Table 1 shows the incidence and observed in-hospital mortality rate of CABG and PCI procedures in California and New York for the time periods studied. CABG mortality was $33 \%$ higher in California, and PCI mortality was nearly twice as high. Procedure performance rates were significantly higher in New York for both CABG and PCI $(P=$ $.0001)$ : in New York $3.0 \%$ of the population undergoes either CABG or PCI compared with California, where the percentage is $2.3 \%$.

\section{Procedural Volume}

During the periods studied, there were 121 hospitals performing $\mathrm{CABG}$ and PCI procedures in California; an additional 17 hospitals performed PCI without CABG facilities. In New York 34 hospitals performed CABG and PCI, and 5 performed PCI alone. Procedural volume and mortality rates for hospitals performing both $\mathrm{CABG}$ and $\mathrm{PCI}$ are 
TABLE 1. Incidence and outcome of CABG and PCI procedures

\begin{tabular}{lcc}
\hline & California & New York \\
\hline Population (year 2000) & $33,871,648$ & $18,976,457$ \\
CABG, n (1999-2001) & 82,353 & 53,220 \\
CABG/1000 persons/y & 0.81 & 0.93 \\
PCI, n (1999-2001) & 153,755 & 117,878 \\
PCI/1000 persons/y & 1.51 & 2.07 \\
CABG mortality, n (\%) & $2431(2.93)$ & $1197(2.25)$ \\
PCI mortality, n (\%) & $2197(1.43)$ & $896(0.76)$
\end{tabular}

Note: All differences in rates between California and New York shown in the table are statistically significant $(P=.0001)$. CABG, Coronary artery bypass grafting; $P C l$, percutaneouscoronary intervention.

shown in Table 2. The data show that the 26 highest-volume hospitals in California, all performing more than $300 \mathrm{CABG}$ procedures per year (average, 516 procedures), had an inhospital mortality of $2.42 \%$ for the 3 -year period, which is comparable with that of New York, with an average volume of 521 procedures per year and a mortality of $2.25 \%(P=$ .32). However, for PCI, high-volume hospitals ( $>600$ procedures per year) still had significantly higher mortality in California $(1.22 \%)$ compared with that in New York $(0.76 \%, P=.0001)$. Risk-adjusted mortality rates reduced the volume effect slightly for CABG mortality and eliminated it for PCI mortality in California.

\section{Risk Factor Comparison}

Table 3 shows selected risk factors for CABG mortality published by the New York State Department of Health in comparison with the California data. Age is reported as "number of years greater than 60 " by New York, which is

\section{TABLE 2. Procedural volume and mortality}

\begin{tabular}{lccc}
\hline Procedure group & $\begin{array}{c}\text { No. of } \\
\text { sites }\end{array}$ & $\begin{array}{c}\text { Average no. of } \\
\text { procedures/y }\end{array}$ & $\begin{array}{c}\text { Mortality, \% } \\
\text { (RAMR) }\end{array}$ \\
\hline CA-CABG $\geq 300 / y$ & 26 & 516 & $2.42(2.58)$ \\
CA-CABG $<300 y$ & 95 & 148 & $3.43(3.22)$ \\
NY-CABG & 34 & 521 & $2.25(2.25)$ \\
$\mathrm{CA}-\mathrm{PCl} \geq 600 / y$ & 22 & 871 & $1.22(1.41)$ \\
$\mathrm{CA}-\mathrm{PCl}<600 / \mathrm{y}$ & 116 & 321 & $1.53(1.39)$ \\
$\mathrm{NY}-\mathrm{PCl}$ & 39 & 1007 & $0.76(0.76)$
\end{tabular}

Note: Mortality for high-volume California hospitals is not statistically significant from mortality in New York hospitals. Mortality in low-volume California hospitals is statistically significantly higher compared with that in (1) high-volume California hospitals or (2) New York hospitals. PCI mortality in low-volume California hospitals is statistically significantly higher compared with that in (1) high-volume California hospitals or (2) New York hospitals. Furthermore, $\mathrm{PCl}$ mortality in high-volume California hospitals is statistically significantly higher compared with that in New York hospitals. $R A M R$, Risk-adjusted mortality rate; $C A$, California; $C A B G$, coronary artery bypass grafting; $N Y$, New York; $P C l$, percutaneous coronary intervention.
TABLE 3. Comparison of selected risk factors: CABG, 19992001

\begin{tabular}{lcccccc}
\hline & \multicolumn{3}{c}{ Prevalence } & & \multicolumn{2}{c}{ Odds ratio } \\
\cline { 2 - 4 } \cline { 7 - 8 } & CA & NY & P value & & CA & NY \\
\hline Female sex & 27.6 & 28.5 & .003 & & 1.37 & 1.87 \\
Diabetes & 32.9 & 32.6 & .2505 & & 0.93 & 1.59 \\
Emergency & 1.83 & 1.10 & .0001 & & 2.37 & 3.54 \\
Shock & 0.96 & 0.42 & .0001 & & 7.75 & 9.00 \\
CVD & 6.84 & 18.8 & .0001 & & 1.23 & 1.77 \\
COPD & 13.6 & 16.6 & .0001 & & 1.45 & 1.99 \\
PVD & 9.76 & 10.9 & .0001 & & 1.41 & 1.94 \\
Renal failure & 3.49 & 1.96 & .0001 & & 3.13 & 2.83 \\
Dialysis & 1.15 & 1.44 & .0001 & & 1.68 & 6.22 \\
Prior CABG & 3.41 & 5.36 & .0001 & & 2.35 & 4.12 \\
CHF or low EF & 15.2 & 22.1 & .0001 & & 2.06 & $1.90-3.50$ \\
\hline
\end{tabular}

$C A$, California; NY, New York; CVD, cerebrovascular disease; COPD, chronic obstructive pulmonary disease; $P V D$, peripheral vascular disease; $C A B G$, Coronary artery bypass grafting; $C H F$, congestive heart failure; $E F$, ejection fraction.

not comparable with California grouped data, but in both states, older age has a significant effect on mortality. Of note is the lack of significance of diabetes as a risk factor in California and the greater significance of female sex in New York. There are fewer emergency and shock cases, a higher incidence of CVD, and a lower incidence of renal failure in New York. We also found that heart catheterization or PCI performed on the same day as CABG significantly affected in-hospital mortality, but these factors were not published in New York reports.

Table 4 shows selected risk factors for PCI mortality published by New York compared with California data. Age was reported as "number of years greater than 55" for PCI, which is not comparable with California grouped data, but

TABLE 4. Comparison of selected risk factors: PCI, 19992001

\begin{tabular}{lcccccc}
\hline & \multicolumn{3}{c}{ Prevalence (\%) } & & \multicolumn{2}{c}{ Odds ratio } \\
\cline { 2 - 4 } \cline { 7 - 8 } & CA & NY & P value & & CA & NY \\
\hline Female sex & 33.0 & 31.9 & .0001 & & 1.25 & 2.88 \\
Diabetes & 25.0 & - & - & & 1.28 & - \\
Emergency & 12.9 & 9.9 & .0001 & & 2.37 & - \\
Shock & 1.17 & 0.29 & .0001 & & 19.23 & 33.0 \\
CVD & 2.64 & 7.22 & .0001 & & 1.50 & 3.08 \\
COPD & 8.23 & 5.53 & .0001 & & 1.51 & 3.10 \\
PVD & 6.22 & 5.72 & .0001 & & 1.54 & 3.54 \\
Renal failure & 2.85 & 1.17 & .0001 & & 2.58 & 5.77 \\
Dialysis & 0.99 & 1.20 & .0001 & & 2.23 & 8.26 \\
CHF or low EF & 10.9 & 11.0 & .4080 & & 1.93 & 3.06 \\
\hline
\end{tabular}

$C A$, California; NY, New York; CVD, cerebrovascular disease; COPD, chronic obstructive pulmonary disease; $P V D$, peripheral vascular disease; $C H F$, congestive heart failure; $E F$, ejection fraction. 


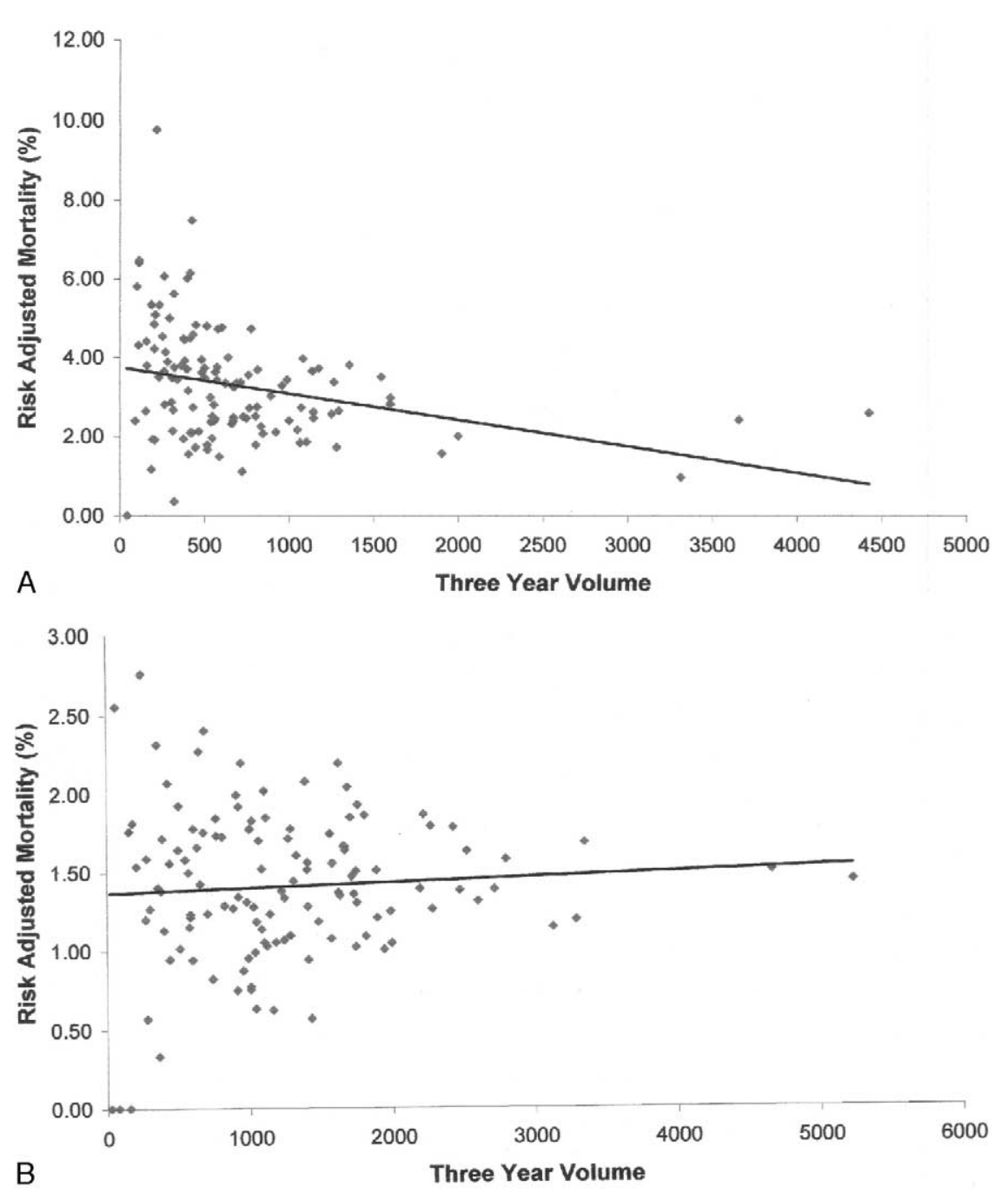

Figure 1. A, Risk-adjusted CABG mortality versus volume. B, Risk-adjusted PCI mortality versus volume.

again older age significantly affected mortality in both states. Diabetes was not reported, and therefore we can assume that it was not a significant risk factor for PCI. Emergency presentation was reported separately by New York for the years 1999-2001; the observed mortality rate was $4.16 \%$ compared with $3.86 \%$ for the emergency presentation group in California. As noted in CABG procedures, there were somewhat fewer emergency and shock patients in New York. Again we see a higher incidence of CVD and a lower incidence of renal failure.

\section{Risk-Adjusted Mortality and Volume Among California Hospitals}

The wide distribution in procedural volume among California hospitals performing both CABG and PCI is illustrated in Figure 1. Each point represents the 3-year volume for one hospital plotted against its risk-adjusted mortality. A volume term added to the logistic regression model indicating whether the patient had CABG surgery at a low-volume as opposed to a high-volume hospital was highly statistically significant (odds ratio, 1.29; 95\% confidence limits, 1.19$1.41 ; P=.0001)$. The scatter plot for CABG shows that the hospitals with a risk-adjusted mortality of greater than $4.0 \%$ all performed less than 300 procedures per year.

Risk adjustment appears to eliminate any effect of volume on mortality from PCI in California. A volume term added to the logistic regression model was not statistically significant in the PCI model.

\section{Increasing Incidence of PCI and Its Effect on CABG Mortality}

Figure 2 illustrates the trend in PCI and CABG procedures in California and New York. Continuation of the trends suggests that PCI might represent more than $70 \%$ of interventional procedures used to treat coronary artery disease by 2004. The increasing incidence of PCI might have an effect on CABG mortality. The highest-volume hospitals in California ( $>600 \mathrm{CABG}$ procedures per year) had the low- 


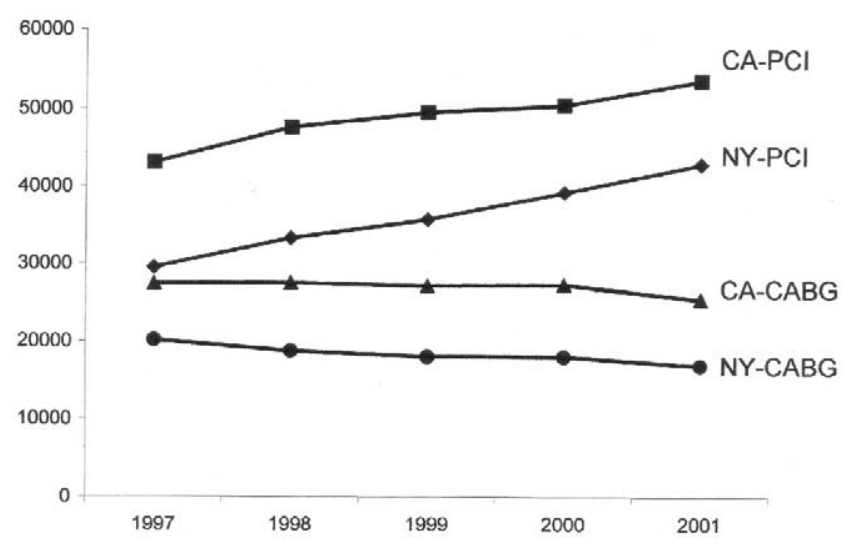

Figure 2. CABG and PCI procedures, California and New York, 1997-2001.

est ratio of PCI volume to CABG volume (1.03) and the lowest risk-adjusted mortality (1.90\%). Among the 97 lowvolume $(<300 \mathrm{CABG}$ procedures per year) hospitals, the $\mathrm{PCI} / \mathrm{CABG}$ ratio was 2.37. The relationship of PCI/CABG ratio to CABG mortality is shown in Figure 3. In our logistic regression model, after controlling for $\mathrm{CABG}$ volume, an indicator term for a PCI/CABG volume ratio of more than 2.0 as opposed to 2.0 or less was highly statistically significant $(P=.0001)$.

\section{Discussion}

In-hospital mortality for CABG procedures has been used as a marker for quality of care in cardiac surgery programs because of the ease of data collection and the accuracy of the end point. Approximately $70 \%$ of cardiac surgery procedures are $\mathrm{CABG}$, and risk-adjustment methods have been refined by collection of more complete clinical data sets, thus making comparisons across hospitals more appropriate. Programs introduced in New York and other states have been associated with reductions in procedural mortality, in part because monitoring of comparative outcomes encourages quality improvement efforts. Collection of clinical data sets for purposes of public reporting has, however, raised concerns about upcoding of risk factors, or avoidance of performing operations on high-risk patients.

In California a voluntary CABG mortality-reporting program was established, but not all hospitals participated, and there were problems with incomplete data submission and accuracy of data coding. Sponsored by the Consumers Union, SB-680 was passed in 2001, requiring mandatory reporting of all medical, surgical, and obstetric procedures, beginning with CABG in 2003. The new program established a Cardiac Advisory Committee that included representatives recommended by the state medical associations. The CCSI was created as a joint project of the California Society of Thoracic Surgeons and the California Healthcare Foundation to assist with compliance with the new law. The CCSI was conceived as a collaborative quality improvement program through which all hospitals could monitor outcomes well before public release and share best practices.

The California medical groups, particularly the thoracic surgeons, were concerned that CABG represented a decreasing percentage of procedures used to treat coronary artery disease. Therefore the CCSI also sought to create a database that included background data on all cardiac surgical and interventional procedures performed in California by using the OSHPD PDD. In a recent report it was found that during 1997-2001, the incidence of PCI increased 24\% in California. ${ }^{2}$ Between 1999 and 2001, PCI increased $16.7 \%$ in New York. There was little change in the number of $\mathrm{CABG}$ procedures performed during this period until

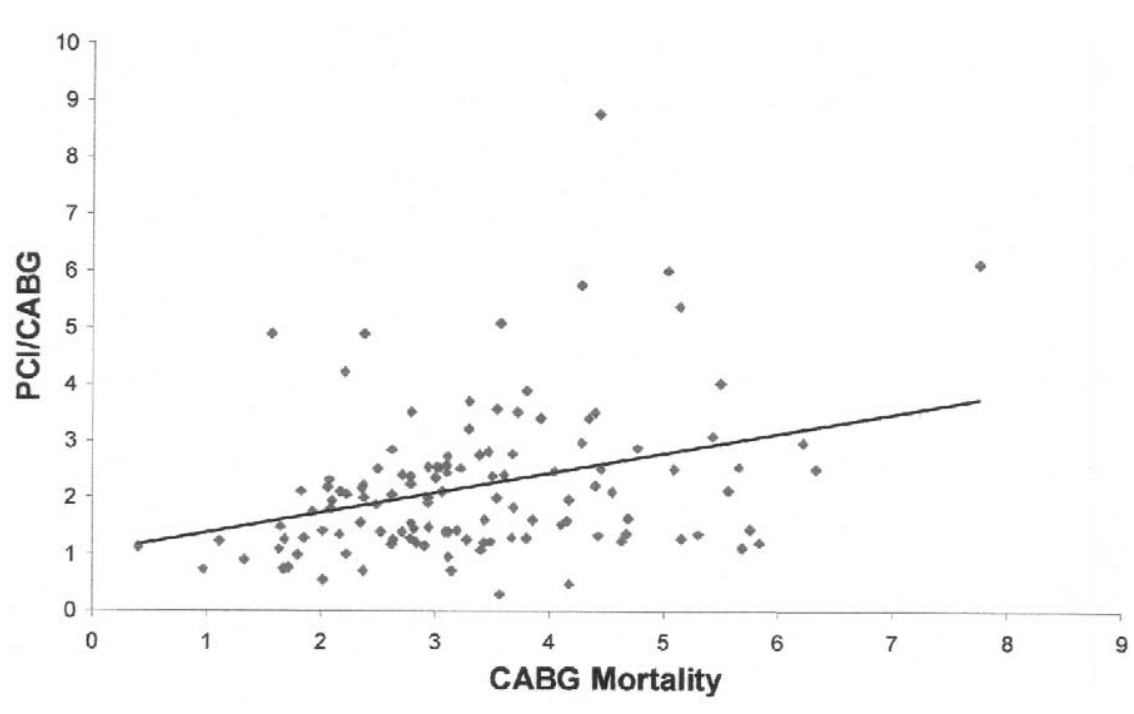

Figure 3. PCI/CABG ratio versus CABG mortality. 
2001, when CABG volume decreased approximately $7 \%$ in both California and New York.

The higher CABG mortality found in California in relation to that seen in New York might be related to the large number of low-volume programs. The highest-volume programs, averaging more than 500 procedures per year, had similar mortality in both states. However, volume as an independent variable has been reported to have a small effect on CABG mortality. Peterson and associates ${ }^{3}$ recently reviewed data from the years 2000 and 2001 in the Society of Thoracic Surgeons National Database, finding that higher volume was marginally predictive of lower mortality (adjusted odds ratio, 0.98; $P=.004$ ). In the present study hospital volume was more clearly associated with CABG mortality (adjusted odds ratio for low-volume vs highvolume hospitals, $1.29 ; P=.0001$ ). This difference might be related to the fact that the Society of Thoracic Surgeons National Database is a voluntary program, whereas all hospitals are included in the California PDD. Hannan and associates, ${ }^{4}$ examining mandatory New York data from 1997-1999, found that significantly lower risk-adjusted mortality rates occurred above all annual hospital volume thresholds between 200 and 800 .

The higher mortality from PCI in California compared with that in New York is more difficult to explain. Comparison of risk factors between the 2 states is confounded by different methods of data collection. Demographic data would suggest that the populations are similar overall. For the most recent census years, the percentage of older $(>65$ years) persons in New York is $13 \%$, and the percentage in California is $11 \%$. The risk models presented here show somewhat more patients with vascular disease in New York and somewhat more patients with acute presentation in California. These differences could be related to data-coding procedures.

PCI in-hospital mortality reported by New York is lower than that reported elsewhere. A recent report from the Agency for Healthcare Research and Quality Nationwide Inpatient Sample hospital discharge database found in-hospital mortality to vary from $1.36 \%$ for high-volume to $2.56 \%$ for low-volume hospitals. ${ }^{4}$ A study from the National Heart, Lung, and Blood Institute Dynamic Registry reported inhospital mortality of $1.0 \%$ to $3.64 \%$, varying with age groups. ${ }^{5}$ In-hospital mortality in Canada during 2000-2001 was $1.4 \%$ for PCI. ${ }^{6}$ In another report from the Nationwide Inpatient Sample, PCI mortality in 1997 was $0.7 \%$ for stented patients in the absence of acute myocardial infarction. ${ }^{7}$ In Scotland, PCI mortality was reported to be $0.3 \%$ during 1997-1999. ${ }^{8}$ Thus PCI mortality in California is similar to that reported in most large registries.

Higher procedure performance rates in New York also suggest that lower PCI mortality is not related to less aggressive use. Hospital volume also is an unlikely cause because higher-volume sites in California did not have better mortality than lower-volume sites. There are more patients with cardiogenic shock and emergency status in California. Although these differences are not large, they might explain some of the findings.

It is more likely that higher PCI mortality in California might be related to case selection. There might be more higher-risk patients selected for PCI than for CABG, such as patients with multivessel disease or complicated lesions. Basic risk factors might appear to be similar, but these disease markers are not included in data-coding systems.

One drawback of this study is the comparison of an administrative and clinical data collection. Although the accuracy of reporting discharge status and the identification of isolated CABG surgeries in the California patient discharge data were found to be good, ${ }^{9}$ one would think that a risk-adjustment model based on clinical data would outperform a risk-adjustment model based on administrative data. Nonetheless, it is doubtful that the magnitude of the volume effect can be attributed to a lack of appropriate risk adjustment in the CABG model.

Programs that perform a relatively large number of PCI procedures and a low volume of $\mathrm{CABG}$ procedures might tend to perform $\mathrm{CABG}$ procedures on a more complex patient population. Our data show that a statistically significant effect of PCI volume on CABG mortality occurs in lower-volume hospitals when the $\mathrm{PCI} / \mathrm{CABG}$ ratio exceeds 2.0. The cause might be related to the reduction in CABG volume and the increase in patient acuity that necessarily follows. More straightforward cases are referred for PCI, and patients with characteristics not defined in risk models, such as poor vessel quality or diffuse disease, tend to be referred to $\mathrm{CABG}$.

The PCI/CABG ratio as a potential risk factor for CABG mortality was alluded to by Starr and associates, ${ }^{10}$ who attempted to explain a lower CABG mortality in health maintenance organization (HMO) referral systems compared with fee-for-service (FFS) systems. Higher patient acuity in FFS patients only partially explained the difference. The PCI/CABG ratio was 0.6 in $\mathrm{HMO}$ and 1.5 in FFS patients. CABG mortality was $2.7 \%$ (HMO) and $4.6 \%$ (FFS).

Clearly, there are more patients undergoing PCI and fewer undergoing $\mathrm{CABG}$ in both California and New York. There might be a relationship in case distribution between PCI and CABG that affects mortality. Further study is indicated.

\section{Conclusions}

We conclude that the higher CABG mortality in California compared with that in New York is related to the large number of low-volume programs in California. Hospitals performing a large number of PCI procedures relative to 
CABG procedures might tend to distribute a more difficult patient population to $\mathrm{CABG}$. These patients might have disease characteristics that are not defined by risk models, such as diffuse multivessel disease that is not amenable to PCI.

PCI mortality is nearly twice as high in California compared with that in New York. This finding is not related to risk factors or hospital procedural volume. It might be related to undefined patient characteristics, patient selection, or timing of intervention.

Procedure performance rates are higher in New York compared with those in California. Overall patient risk appears to be similar in the 2 states.

$\mathrm{PCI}$ is increasing (and CABG decreasing) in both California and New York. PCI will represent more than $70 \%$ of revascularization procedures by 2004 .

\section{References}

1. Carey JS, Robertson JM, Misbach GA, Fisher AL. Relationship of hospital volume to outcome in cardiac surgery programs in California. Am Surg. 2003;69:63-8.

2. Carey JS, Danielsen B, Jamieson S, Rossiter SJ. Incidence and outcomes of coronary revascularization procedures in California. Paper presented at: American College of Surgeons Southern California Chapter meeting; Santa Barbara (CA): January 17, 2004.

3. Peterson ED, Coombs LP, DeLong ER, et al. Procedural volume as a marker of quality for CABG surgery. JAMA. 2004;291:195-201.

4. Hannan EL, Wu C, Ryan TJ, et al. Do hospitals and surgeons with higher coronary artery bypass graft surgery volumes still have lower risk-adjusted mortality rates? Circulation. 2003;108:795-801.

5. Epstein AJ, Rathore SS, Volpp KG, Krumholz HM. Hospital percutaneous coronary intervention volume and patient mortality, 1998 to 2000: does the evidence support current procedure volume minimums? J Am Coll Cardiol. 2004;43:1755-62.

6. Cohen HA, Williams Do, Holmes DR Jr, et al. Impact of age on procedural and 1-year outcome in percutaneous transluminal coronary angioplasty: a report from the NHLBI Dynamic Registry. Am Heart J. 2003;146:513-9.

7. Maynard C, Every NR, Chapko MK, Ritchie JL. Improved outcomes associated with stenting in the healthcare cost and utilization project. J Interv Cardiol. 2001;14:159-63.

8. Pell JP, Walsh D, Norrie J, et al. Outcomes following CABG and PCI in the stent era: a prospective study of all 9890 consecutive patients operated on in Scotland over a two year period. Heart. 2001;85:662-6.

9. The California Report on Coronary Artery Bypass Graft Surgery 1999 Hospital Data. Technical Report, March 2004. Available at: www.oshpd. state.ca.us. Accessed June 2004.

10. Starr A, Furnary AP, Grunkemeier GL, He GW, Ahmad A. Is referral source a risk factor for coronary surgery? Health maintenance organization versus fee-for service system. J Thorac Cardiovasc Surg. 1996;111:705-7.

\section{Bound volumes available to subscribers}

Bound volumes of The Journal of Thoracic and Cardiovascular Surgery are available to subscribers (only) for the 2005 issues from the Publisher, at a cost of $\$ 134.00$ for domestic, $\$ 165.85$ for Canadian, and $\$ 155.00$ for international subscribers for Vol 129 (January-June) and Vol 130 (July-December). Shipping charges are included. Each bound volume contains a subject and author index.

The binding is durable buckram with the Journal name, volume number, and year stamped in gold on the spine. Payment must accompany all orders. Contact Elsevier Inc., Subscription Customer Service, 6277 Sea Harbor Dr, Orlando, FL 32887, USA; phone 800-654-2452 or 407-345-4000.

Subscriptions must be in force to qualify. Bound volumes are not available in place of a regular Journal subscription. 